
\title{
$\begin{array}{ll}\text { Research Square } & \begin{array}{l}\text { Preprints are preliminary reports that have not undergone peer review. } \\ \text { They should not be considered conclusive, used to inform clinical practice, } \\ \text { or referenced by the media as validated information. }\end{array}\end{array}$
}

\section{Synthesis, Characterization and Properties of Nitrogen Doped Carbon Nanotubes}

\section{Quping Zhu ( $\nabla$ sspulpzhu@163.com )}

Chongqing Institute of Engineering https://orcid.org/0000-0003-1275-9375

\section{Original Research}

Keywords: nitrogen doped carbon nanotubes, synthesis, properties

Posted Date: February 8th, 2021

DOI: https://doi.org/10.21203/rs.3.rs-192756/v1

License: (c) (i) This work is licensed under a Creative Commons Attribution 4.0 International License. Read Full License

Version of Record: A version of this preprint was published at Journal of Materials Science: Materials in Electronics on March 12th, 2021. See the published version at https://doi.org/10.1007/s10854-02105631-0. 


\section{Abstract}

In this work, nitrogen doped carbon nanotubes (N-CNTs) were prepared by a facile chemical vapor deposition method using Fe/SBA-15 molecular sieve as the catalyst and different organic amines as carbon source and nitrogen source. The morphology, structure and composition of the obtained samples were characterized by a series of analytical techniques. The results revealed that the as-obtained N-CNTs are hollow bamboo like nanofibers with a diameter of 30-50 nm and a smooth surface. The effect of the organic amines on the yield, composition, morphology and properties of the N-CNTs were investigated. The N-CNTs prepared with diethylamine (DEA) have the highest yield $\left(2.2 \mathrm{~g} \cdot(\mathrm{g} \cdot \mathrm{cat})^{-1}\right)$. The water absorption of the as-synthesized N-CNTs samples increases with the increase of nitrogen content. The NCNTs prepared with ethylenediamine (EDA) have the highest $\mathrm{N} / \mathrm{C}$ molar ratio(0.35) and the highest water absorption (224.4 $\left.\mathrm{mg} \cdot \mathrm{g}^{-1}\right)$. The thermal conductivity (TC) of the silicon-based composites increases with the increase of N-CNTs. However, the N/C molar ratio of N-CNTs has a negative effect on the TC of silicon-based composites.

\section{Introduction}

Since the discovery of carbon nanotubes (CNTs) by lijima in 1991[1], due to their excellent physical and chemical properties, their synthesis, characterization and properties have become one of the research hotspots in recent years[2]. Although pure carbon nanotubes (CNTs) have the advantages of high strength, high toughness, good thermal stability and electrical conductivity, there are some problems in practical application, such as poor dispersion, poor hydrophilicity and poor selective adsorption performance, which greatly limits its practical application. Many studies have shown that the construction of composite materials, doping or surface chemical modification can overcome the shortcomings of the CNTs and improve their conductivity and electrochemical properties [3-7]. Nitrogen is considered to be a good dopant because the size of nitrogen atom is very close to that of carbon, which is easy to enter into the lattice of CNTs[8,9]. Considerable efforts have been made to prepare nitrogen doped carbon nanotubes (N-CNTs) and study their physical and chemical properties. [3, 4, 10-19]. For example, Bi et al.[12] prepared N-CNTs by one-step pyrolysis method. The specific surface area of the prepared N-CNT is $1009 \mathrm{~m}^{2} / \mathrm{g}$, which is 1.5 times that of the intrinsic CNTs. The maximum power density and current density of microbial fuel cells (MFCs) by using the as-synthesized N-CNTs as anode material of MFCs can reach $2777 \mathrm{mw} / \mathrm{m}^{2}$ and $15 \mathrm{~mA} / \mathrm{cm}^{2}$, respectively. They believe that nitrogen doping not only provides a high density of active sites for electrochemical reaction, but also increases the surface defects of CNTs, thus enhancing the biocompatibility of MFCs. Prithi et al.[16] synthesized N-CNT with N mass fraction of $11 \%$ and $6 \%(11 \% \mathrm{~N}-\mathrm{CNTs}$ and $6 \% \mathrm{~N}-\mathrm{CNT})$ by colloidal silicon assisted sol gel method. It was found that PEMFCs with $1.1 \% \mathrm{~N}$-CNTs as the support of Pt catalyst exhibit larger active area and higher limiting current, and their power density is 1.8 times that of the proton exchange membrane fuel cells (PEMFCs) with 6\% N-CNTs as the support of Pt catalyst. This result shows that the higher $\mathrm{N}$ content of $11 \% \mathrm{~N}$-CNTs, especially the higher pyridine $\mathrm{N}$ content, makes its catalytic performance better than that of the latter. Nonomura et al[19]. prepared vertically aligned $\mathrm{N}-\mathrm{CNTs}$ in $\mathrm{NH}_{3}$ atmosphere at $300-600{ }^{\circ} \mathrm{C}$ 
through the heat treatment of the fluorinated vertically aligned multi-walled CNTs and used them as electrode materials for electrochemical capacitors. It was found that the specific capacitance of $\mathrm{N}$-doped vertically aligned multi-walled CNTs capacitor is about $12 \mathrm{~F} / \mathrm{g}$, which is nearly twice as high as that of undoped vertically aligned multi-walled CNTs capacitor. Obviously, nitrogen doping can significantly affect the physical and chemical properties of the CNTs. However, as far as we know, the research on the effect of $\mathrm{N}$ content on the properties of the N-CNTs is still insufficient. It is necessary to further study the effect of the $\mathrm{N}$ content on the properties of the N-CNTs.

In this paper, we presented the preparation of the N-CNTs with different N content by chemical vapor deposition using Fe/SBA-15 molecular sieve as catalyst and different organic amines as carbon source and nitrogen source. The morphology and chemical composition of the materials were characterized by transmission electron microscopy (TEM), X-ray diffraction (XRD), fourier transform infrared (FT-IR), Raman spectroscopy and X-ray photoelectron spectroscopy (XPS), etc. The effects of different organic amines on the yield, nitrogen content and water absorption of the N-CNTs were investigated. The relationship between nitrogen content and thermal conductivity of silicon-based composites was analyzed.

\section{Experimental}

\subsection{Synthesis of N-CNTs}

The N-CNTs were obtained by a modified chemical vapor deposition (CVD)with Fe-containing SBA-15 molecular sieve as the catalyst and ethylene diamine(EDA) as the nitrogen and carbon sources. In a typical synthesis procedure, First, a small porcelain boat containing $0.5 \mathrm{~g} \mathrm{Fe} / \mathrm{SBA}-15$ catalyst was placed in a tubular furnace and heated to $800{ }^{\circ} \mathrm{C}$ in flowing nitrogen $\left(60 \mathrm{ml} \mathrm{min}^{-1}\right)$ for $30 \mathrm{~min}$. Then, the $\mathrm{Ar} / \mathrm{EDA}$ mixture were introduced at the flow rate of $20 \mathrm{ml} \cdot \mathrm{min}^{-1}$, and maintained at $800{ }^{\circ} \mathrm{C}$ for $2 \mathrm{~h}$. Finally, the obtained black powder was soaked in hydrofluoric acid for several hours to remove the catalyst, washed to neutral with deionized (DI) water, and dried at $60^{\circ} \mathrm{C}$. The N-CNTs samples prepared with EDA as organic amines were marked as N-CNTs-E. In order to investigate the effects of different organic amines on the yield, composition, morphology and properties of the products, N-CNTs were also prepared using triethylamine (TEA) and diethylamine (DEA) as raw materials, respectively. They were marked as N-CNTsT and N-CNTs-D, respectively.

\subsection{Characterization}

The phase purity and composition of the products were characterized by X-ray diffractometer (XRD, D8 Advance, Bruker, Germany). The morphologies, microstructures and nitrogen contents of the as-prepared samples were examined by using scanning electron microscope (SEM, HITACHI S-4800, Japan) equipped with an energy dispersive X-ray spectrometer (EDS) and transmission electron microscope (TEM, JEM 2100F, Japan). The fourier transform infrared (FT-IR) and Raman spectra of the as-prepared samples were recorded using a Varian 3100 FT-IR spectrometer and a Renishaw inVia Raman microscope, 
respectively. Thermogravimetric and differential scanning calorimetry analyses (TGA-DSC) were performed by a Netzsch STA-449C analyzer with a heating rate of $10^{\circ} \mathrm{C} \mathrm{min}^{-1}$. The X-ray photoelectronspectroscopy (XPS) analysis was performed on an Axis Ultra DLD instrument from Kratos (UK) using an Al Ka X-ray radiation source at a power of $300 \mathrm{~W}$. The water absorption value is determined by measuring the weight gain value of the material adsorbed in the vapor of saturated sodium chloride aqueous solution at $308 \mathrm{~K}$ for $24 \mathrm{~h}$. The thermal conductivity (TC) of the synthesized N-CNTs samples was evaluated by measuring the enhancement rate of the TC of the silicon-based composites using a thermal conductivity analyzer (C-Therm TCi, Canada).

\section{Results And Discussion}

Fig. 1 is the XRD pattern of the N-CNTs samples prepared with ethylene diamine (EDA). It can be seen that the as-synthesized N-CNTs (N-CNTs-E) samples exhibits two characteristic diffraction peaks at $2 \theta$ values of $26.1^{\circ}$ and $42.9^{\circ}$, corresponding to the (002) and (101) crystal planes of graphite carbon [20, 21]. However, compared with undoped CNTs (Fig. S1), the characteristic diffraction peaks of the assynthesized N-CNTs-E samples move slightly towards the lower $2 \theta$ value. This may be due to the slight distortion of carbon crystal caused by the introduction of nitrogen atom [22, 23].

The morphology and structure of the as-synthesized N-CNTs-E samples were investigated by fieldemission SEM and TEM, as shown in Fig. 2. Fig. 2 (a) shows the SEM image of the as-prepared N-CNTs-E. It is clearly seen that the as-synthesized N-CNTs-E samples with a diameter of about $30-50 \mathrm{~nm}$ are very clean and have a smooth surface. The TEM image (Fig. 2 (b)) revealed that the as-synthesized N-CNTs-E samples have bamboo like hollow structure, which is consistent with the typical characteristics of the NCNTs as widely reported[6, 24,25]. This may be caused by the periodic formation and spalling of nitrogen doped graphitic layers from the catalyst surface [26].

The FTIR and Raman spectra of the as-synthesized N-CNTs-E samples were showed in Fig.3. Fig. 3(a) shows the FTIR spectrum of the as-prepared N-CNTs-E. The peak at $3420 \mathrm{~cm}^{-1}$ corresponds to -OH group, which is mainly due to water adsorption. The peak at $2937 \mathrm{~cm}^{-1}$ should be assigned to $\mathrm{CH}_{2}$ group. In addition, there is a peak at $1461 \mathrm{~cm}^{-1}$, which should be attributed to $\mathrm{C}=\mathrm{N}$ in pyridine group. The peak at $1646 \mathrm{~cm}^{-1}$ can be assigned to the $\mathrm{C}=\mathrm{C}$ in the graphitic layers of CNTs. As well known, Raman spectroscopy is a versatile and non-destructive characterization technique for carbon materials, especially for conjugated and carbon-carbon double bonds, which can lead to high Raman intensities $[27,28]$. In order to further characterize the molecular structure and chemical bond, the as-synthesized NCNTs-E samples were detected by Raman spectroscopy. The Raman spectrum of the as-synthesized NCNTs-E samples was showed in Fig. 3(b), which revealed that the as-synthesized N-CNTs-E samples have three different peaks. The peak position at $\sim 1575 \mathrm{~cm}^{-1}$ (marked as $\mathrm{G}$ ) is related to the in-plane bond stretching motion of $s p^{2}$ carbon atoms in the graphitized structure [29]. The peak position at $\sim 1350 \mathrm{~cm}^{-1}$ (marked as $\mathrm{D}$ ) shows the breathing mode of $s p^{3}$ rings, which is related to bond-angle disorder, bondlength disorder, and hybridization [30]. The peak position at $\sim 2700 \mathrm{~cm}^{-1}$ (marked as G') reveals the 
existence of doping in CNTs. The thermogravimetric curves (Fig. S2) showed that the as-synthesized NCNTs-E samples have good thermal stability.

To further determine the chemical state and composition of the as-synthesized N-CNTs-E samples, X-ray photoelectron spectroscopy (XPS) measurement was carried out in the region of $0-1100 \mathrm{eV}$. The fully scanned spectra (Fig. 4 (a)) demonstrate that $\mathrm{N}$ and $\mathrm{C}$ elements exist in the as-synthesized N-CNTs-E samples. The high-resolution XPS spectrum of N1s was showed in Fig. 4 (b). It shows that the XPS spectrum of $\mathrm{N} 1 \mathrm{~s}$ scan is composed of two peaks, which are 399.1 and $400.2 \mathrm{eV}$, respectively. The peak (P1) at $399.1 \mathrm{eV}$ can be assigned to the pyridine-like N; while the peak (P2) at $400.2 \mathrm{eV}$ can be assigned to the graphite-like $\mathrm{N}$. The pyridine-like $\mathrm{N}$ corresponds to the $\mathrm{N}$ atoms occupying the vacancy formed by removing a central $\mathrm{C}$ atom among three hexagons and replacing the three surrounding $\mathrm{C}$ atoms with three $\mathrm{N}$ toms. ${ }^{23}$ The pyridine-like $\mathrm{N}$ has two extra nonbonding electrons in its $\mathrm{sp}^{2}$-hybridized orbital, which can act as a nonbonding p-orbital.

In order to investigate the effect of the organic amines on the yield, composition, morphology and properties of the N-CNTs, a series of experiments and characterization were carried out. Fig. 5 showed the FE-SEM images of the N-CNTs samples prepared with triethylamine (TEA) and diethylamine (DEA). It can be seen from Fig. 5 that there is no significant difference in the appearance of N-CNTs prepared with different organic amines, and the diameters are all $30-50 \mathrm{~nm}$. It is worth noting that with the increase of nitrogen content in organic amines, the yield of N-CNTs increases significantly, and the N/C molar ratio of the N-CNTs samples also increases sharply. The results are shown in Fig. 6 . When the ratio N/C of organic amine is 0.17 , such as triethylamine $\left(\mathrm{C}_{6} \mathrm{H}_{15} \mathrm{~N}, \mathrm{CH}_{2.5} \mathrm{~N}_{0.17}\right)$, the yield of the $\mathrm{N}-\mathrm{CNTs}$ (N-CNTs-T) samples is $1.7 \mathrm{~g} \cdot(\mathrm{g} \mathrm{cat})^{-1}$. When the ratio of $\mathrm{N} / \mathrm{C}$ is increased to 0.25 , such as diethylamine $\left(\mathrm{C}_{4} \mathrm{H}_{11} \mathrm{~N}\right.$, $\mathrm{CH}_{2.75} \mathrm{~N}_{0.25}$ ), the yield of the N-CNTs (N-CNTs-D) samples is increased rapidly, reaching $2.2 \mathrm{~g} \cdot(\mathrm{g} \mathrm{cat})^{-1}$. However, excessive nitrogen may lead to the instability of the product and decrease the yield. For example, when the ratio $\mathrm{N} / \mathrm{C}$ of organic amine is 1 , such as ethylenediamine $\left(\mathrm{C}_{2} \mathrm{H}_{8} \mathrm{~N}_{2}, \mathrm{CH}_{4} \mathrm{~N}\right)$, the yield of the $\mathrm{N}-\mathrm{CNTs}(\mathrm{N}-\mathrm{CNTs}-\mathrm{E})$ is only $0.68 \mathrm{~g} \cdot(\mathrm{g} \text { cat })^{-1}$. Therefore, the suitable nitrogen content in organic amine, i.e. N/C ratio, is very important to increase the yield of the N-CNTs products. The corresponding XRD patterns of the the N-CNTs products prepared with different organic amines are also displayed in the Fig. S1. All these N-CNTs exhibits two characteristic diffraction peaks at $2 \theta$ values around $26.1^{\circ}$ and $42.9^{\circ}$ which correspond to the (002) and (101) plane diffractions from graphitic carbon $[19,20]$. Similar to the $\mathrm{N}-\mathrm{CNTS}$-E samples, the diffraction peaks of the N-CNTs-T and N-CNTs-D samples are also shifted to lower $2 \theta$ values.

Fig. 7 shows the water absorption of the N-CNTs prepared with different organic amines. It can be seen from Fig. 7 that with the increase of nitrogen content in organic amines, the N/C molar ratio in the prepared nitrogen doped carbon nanotubes will gradually increase, and the water absorption value can also be significantly increased. For example, when the molar ratio of $\mathrm{N} / \mathrm{C}$ in the samples is 0.06 (i.e. $\mathrm{N}$ CNTs-T), the water absorption value is only $98.1 \mathrm{mg}^{-1} \mathrm{~g}^{-1}$, but when the molar ratio of $\mathrm{N} / \mathrm{C}$ is 0.35 (i.e. $\mathrm{N}$ CNTs-E), the water absorption value can reach $224.4 \mathrm{mg} \cdot \mathrm{g}^{-1}$, which is more than two times higher than 
that of the N-CNTs-T samples. Obviously, the more nitrogen content in the raw materials, that is, the greater the N/C of organic amines, the more nitrogen elements in the N-CNTs samples, and correspondingly, the stronger the water absorption capacity. This may be due to the introduction of nitrogen to increase the polarity of carbon skeleton (C-N bond is more polar than $\mathrm{C}-\mathrm{C}$ bond), which is beneficial to improve the water absorption performance of the N-CNTs products.

Fig. 8 shows the effect of the N-CNTs samples prepared with different organic amines on TC of siliconbased composites. It is clearly revealed that the N-CNTs samples prepared with different organic amines can effectively enhance the thermal conductivity of silicon-based composites. However, it should be noted that the improvement of thermal conductivity of silicon-based composites by the as-synthesized NCNTs samples is negatively correlated with the nitrogen content, or nitrogen doping degree in the N-CNTs samples. This may be attributed to the defects caused by nitrogen doping, which act as phonon scattering centers, resulting in decrease of thermal conductivity [14]. The defects of the N-CNTs can be explained by Raman spectroscopy. The Raman spectra of the N-CNTs samples prepared with different organic amines were showed in Fig. S3. It can be seen from Fig. S3 that the intensity ratio of D peak to G peak increases with the increase of nitrogen content in the N-CNTs. Generally, the introduction of nitrogen atoms in CNTs weakens the order of graphite network to a certain extent, resulting in defects. So, the more nitrogen atoms are introduced, the more defects in the N-CNTs structure. This is a good explanation why the TC of the N-CNTs decreases with the increase of nitrogen content.

\section{Conclusions}

Nitrogen doped carbon nanotubes (N-CNTs) were prepared by a facile chemical vapor deposition method using organic amines as the nitrogen and carbon sources. The morphology, structure and composition of the obtained samples were characterized by a series of analytical techniques. The effect of the organic amines on the yield, composition, morphology and properties of the N-CNTs were investigated. The water absorption of the as-synthesized N-CNTs samples increases with the increase of $\mathrm{N}$ content. The thermal conductivity (TC) of the silicon-based composites increases with the increase of N-CNTs. However, the $\mathrm{N} / \mathrm{C}$ molar ratio of N-CNTs has a negative effect on the TC of silicon-based composites. This was attributed to defects in the N-CNTs, which acted as phonon scattering centers, resulting in decrease of thermal conductivity.

\section{Declarations}

\section{Acknowledgments}

This research was jointly sponsored by the National Natural Science Foundation of China (51778096), and the Guangxi Key Laboratory of Information Materials (GUET) (No:171011-K).

\section{References}


1. lijima. Nature 354 (1991) 56-58.

2. S. Dresselhaus, G. Dresselhaus, P. Avouris, Carbon nanotubes: synthesis, structure, properties and applications, Springer, Berlin, 2000.

3. N. Volkov, L.V. Zhigilei. Appl. Phys. Lett. 101 (2012) 043113.

4. Scardamaglia, C. Struzzi, F.J.A. Rebollo, P. de Marco, P.R. Mudimela, J. F. Colomer, M. Amati, L. Gregoratti, R. Snyders, C. Bittencourt. Carbon 83 (2015) 118-127.

5. I. Ionescu, Y. Zhang, R. Li, H. Abou-Rachid, X. Sun. App. Surf. Sci. 258 (2012) 4563-4568.

6. Cao, H. Yu, J. Tan, F. Peng, H. Wang, J. Li, W. Zheng, N.B. Wong. Carbon 57 (2013) 433-442.

7. Liu, Y. Zhang, Y. Lin, Z. Zhao, Q. Li. Carbon 69 (2014) 247-254.

8. Ji, S. Niu, Y. Du, B. Song, P. Xu. ACS Sustainable Chem. Eng. 6(9)(2018) 11922-11929.

9. Kim, N. P. Zussblat, H. Chung, S. M. Becwar, P. Zelenay, B. Chmelka, ACS Appl. Mater. Interfaces. 10(30)(2018)25337-24343.

10. An, S. Dong. J. Nanjing Tech Univercity (Natural Science Edition) 41(2019) 395-402.

11. Jin, X. Yang, Y. Ou, M. Rao, Y. Zhong, G. Zhou, D. Ye, Y. Qiu, Y. Wu, W. Li. Sci. Bull. 65 (2020) 452-459.

12. Bi, S. Ci, P. Cai. Appl. Surf. Sci. 427(2018)10-15.

13. Yan, C. Zhang, F. Yuan, C. Qin. Chem. J. Chin. Universities 41(2020)2503-2510.

14. S. Yang, J. Y. L, S. W. Jo. Int. J. Hydrogen Energy 43(3)(2017)1516-1520.

15. Hou, B. Chi, G. Liu. Electrochim. Acta 253(2017)142-148.

16. A. Prithi, N. Rajalakshmi, G. R. Rao. Int. J. Hydrogen Energy 43(9)(2017)4716-4721.

17. Wang, L. Zhu, N. Bing, L. Wang. J. Phys. Chem. Solids 107(2017)125-130.

18. Zhu, L. Wang, N. Bing, P. Li, L. Wang, C. Huang, G. Liao. RSC Adv. 6(2016)2926-2931.

19. Nonomura, T. Itoh, Y. Sato. Carbon 132(2018)539-544.

20. Xia, R. Mokaya. Chem. Mater. 17 (2005) 1553-1560.

21. Dong, X. Qu, L. Wang, C. Zhao, J. Xu. Electroanalysis 20 (2008) 1981-1986.

22. Lim, S.H. Yoon, I. Mochida, D.H. Jung. Langmuir 25 (2009) 8268-8273.

23. Qu, Y. Liu, J.B. Baek, L. Dai. ACS nano 4 (2010) 1321-1326.

24. W. Jang, C.E. Lee, S.C. Lyu, T.J. Lee, C.J. Lee. Appl. Phys. Lett. 84 (2004) 2877-9.

25. G. Sumpter, V. Meunier, J.M. Romo-Herrera, E. Cruz-Silva, D.A. Cullen, H. Terrones, D.J. Smith, M.

Terrones. ACS Nano 1 (2007) 369-75.

26. V. Dommele, A. Romero-Izquirdo, R. Brydson, K.P. de Jong, J.H. Bitter. Carbon 46 (2008) 138-48.

27. C. Zhao, J.H. Wu, M. Zheng, J.H. Huo, Y.J. Tu. Electrochim. Acta 96 (2013) 110-116.

28. N. Kudin, B. Ozbas, H.C. Schniepp, R.K. Prud'homme, I.A. Aksay, R. Car. Nano Lett. 8 (2008) 36.

29. S. Dresselhaus, A. Jorio, M. Hofmann, G. Dresselhaus, R. Saito. Nano Lett. 10 (2010) 751-758.

30. Jorio, M.A. Pimenta, A.G.S. Filho, R. Saito, G. Dresselhaus, M.S. Dresselhaus. New J. Phys. 5 (2003) 1765-1768. 
31. Li, N. Chopra. Carbon 77 (2014) 675-687.

Figures

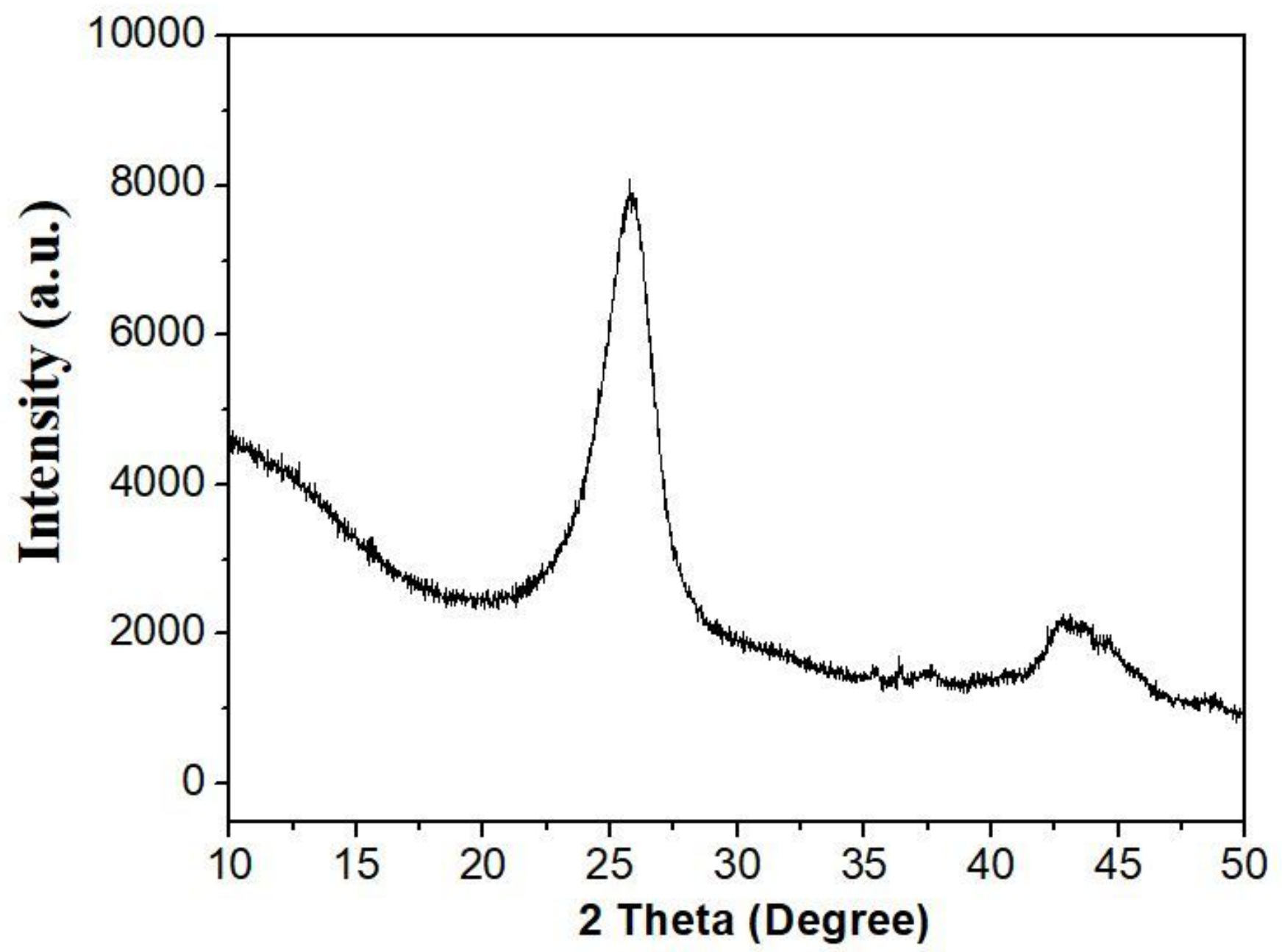

Figure 1

The XRD pattern of the N-CNTs-E. 

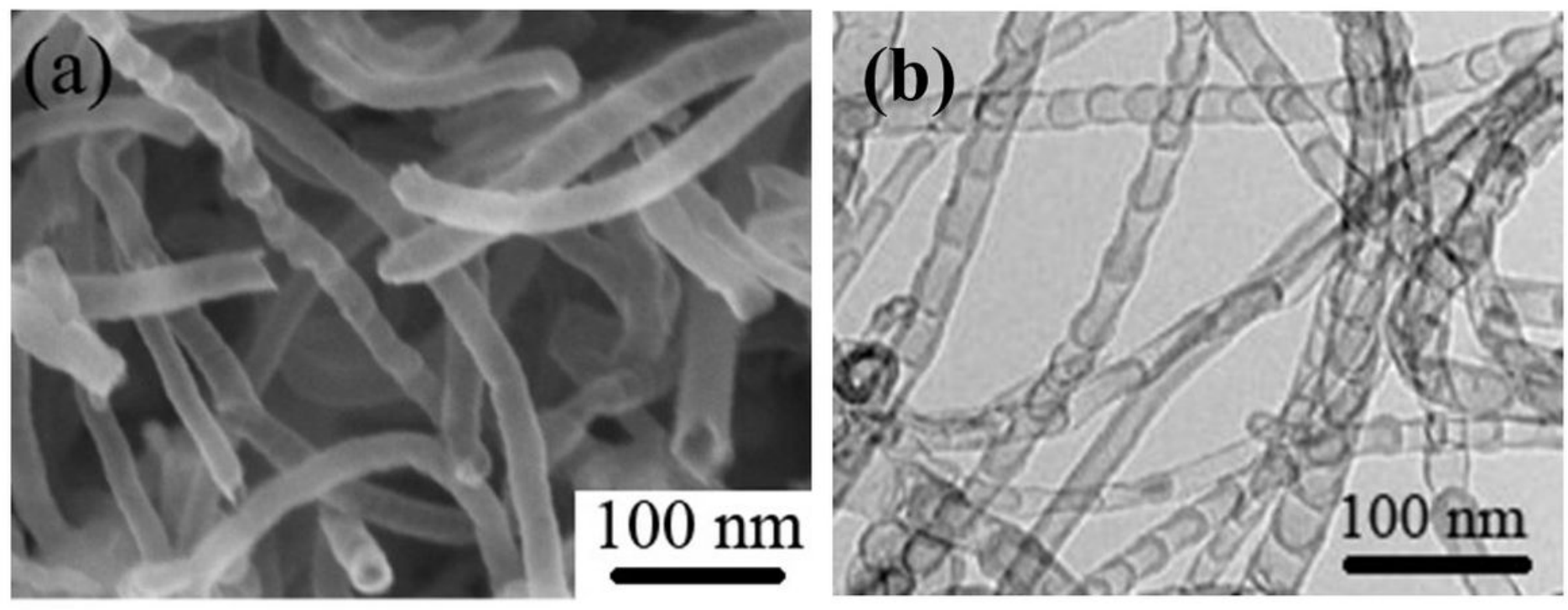

Figure 2

The FE-SEM (a) and TEM (b) images of the N-CNTs-E.
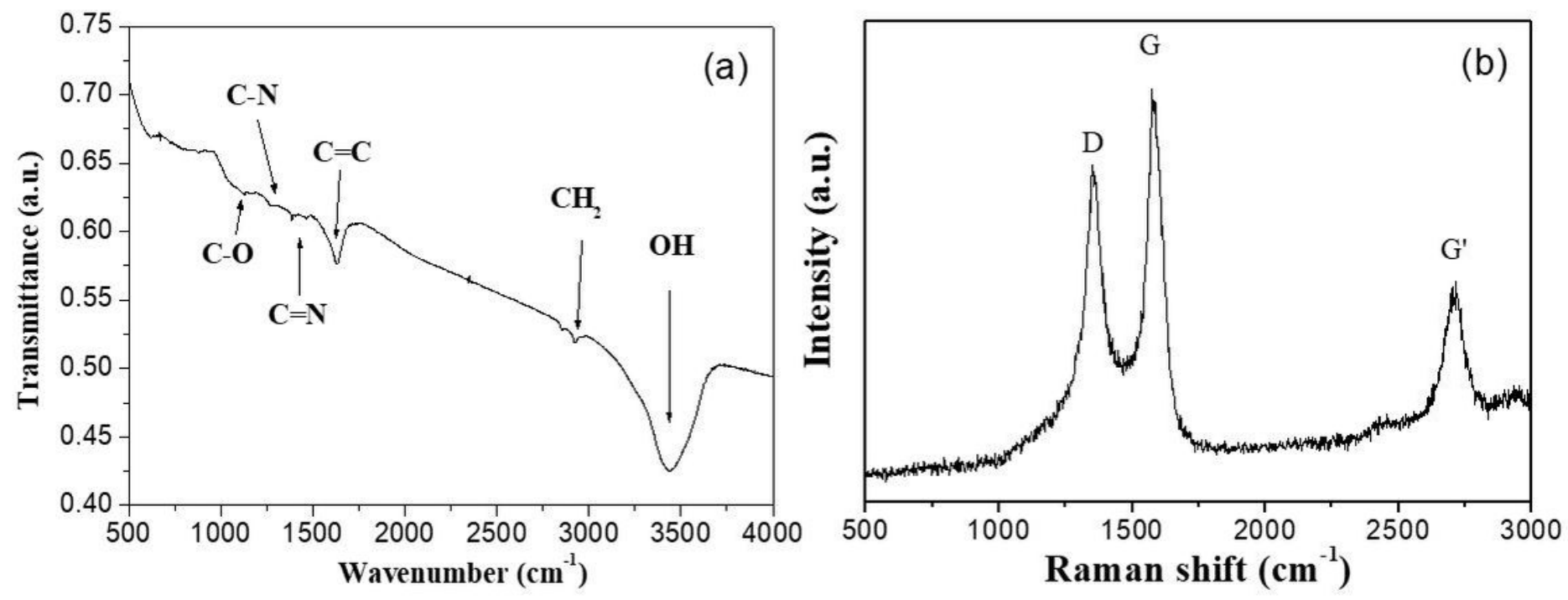

Figure 3

The FTIR (a) and Raman (b) spectra of the N-CNTs-E. 

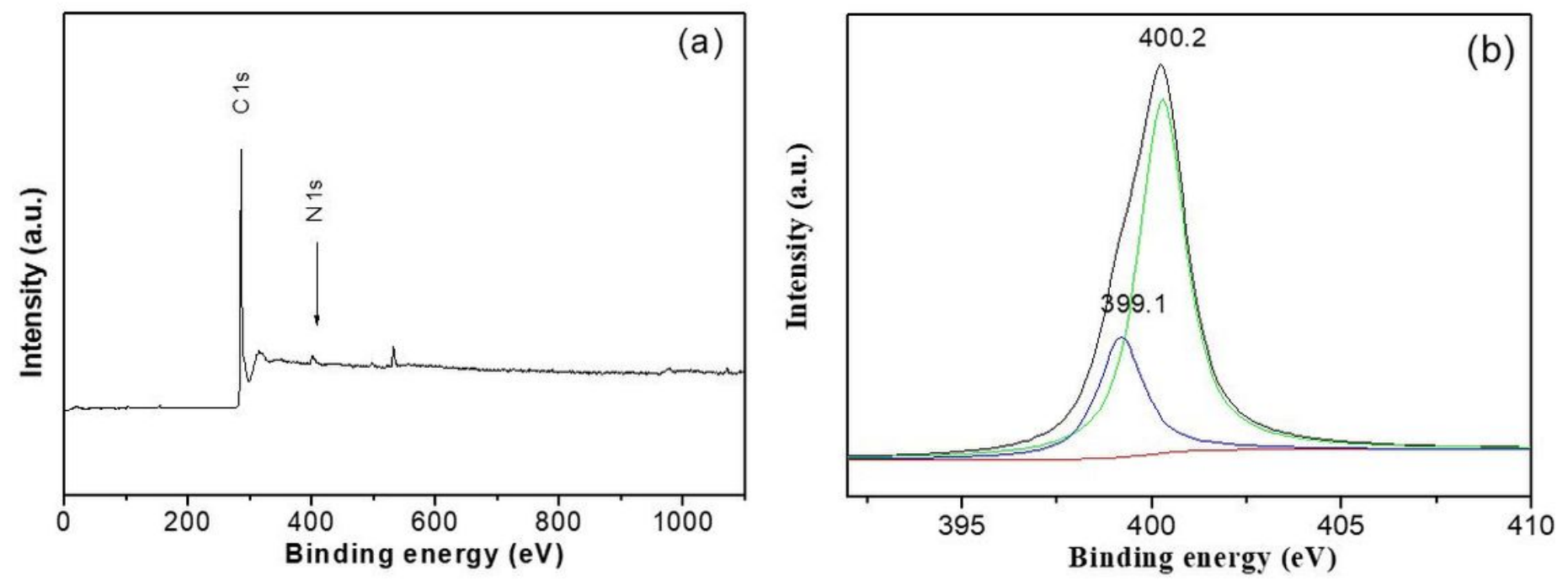

Figure 4

(a)XPS survey spectrum of the N-CNTs-E. (b) High-resolution XPS spectrum of the N1s.
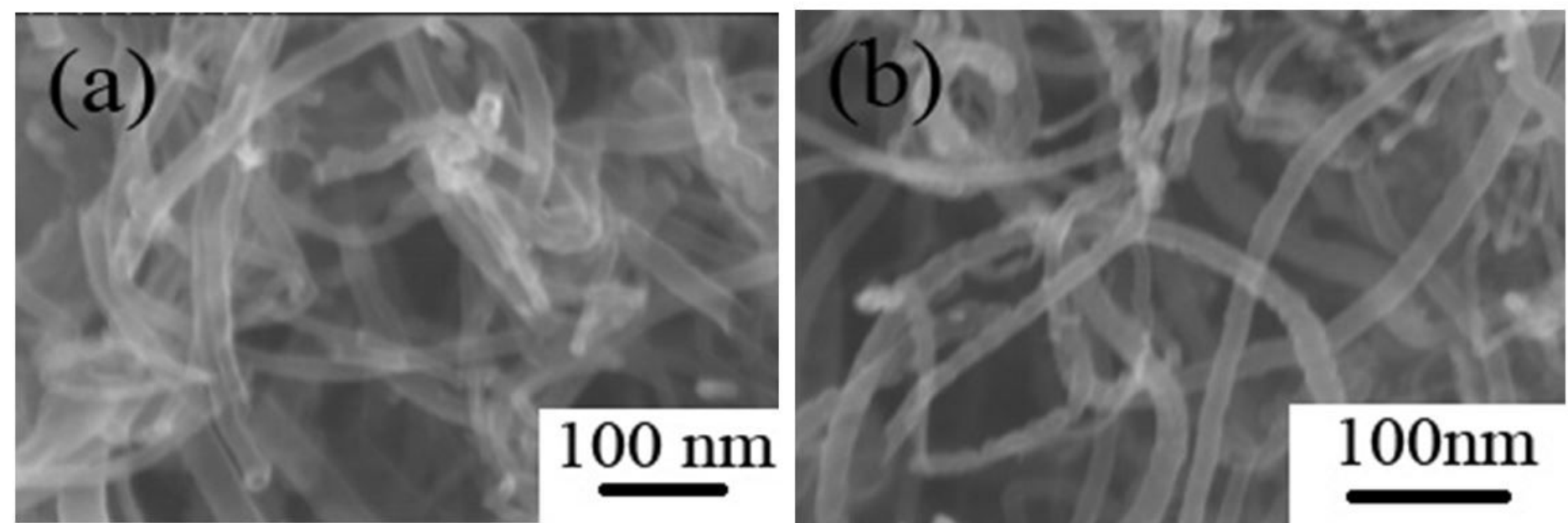

Figure 5

FE-SEM images of the N-CNTs-T (a) and N-CNTs-D (b). 


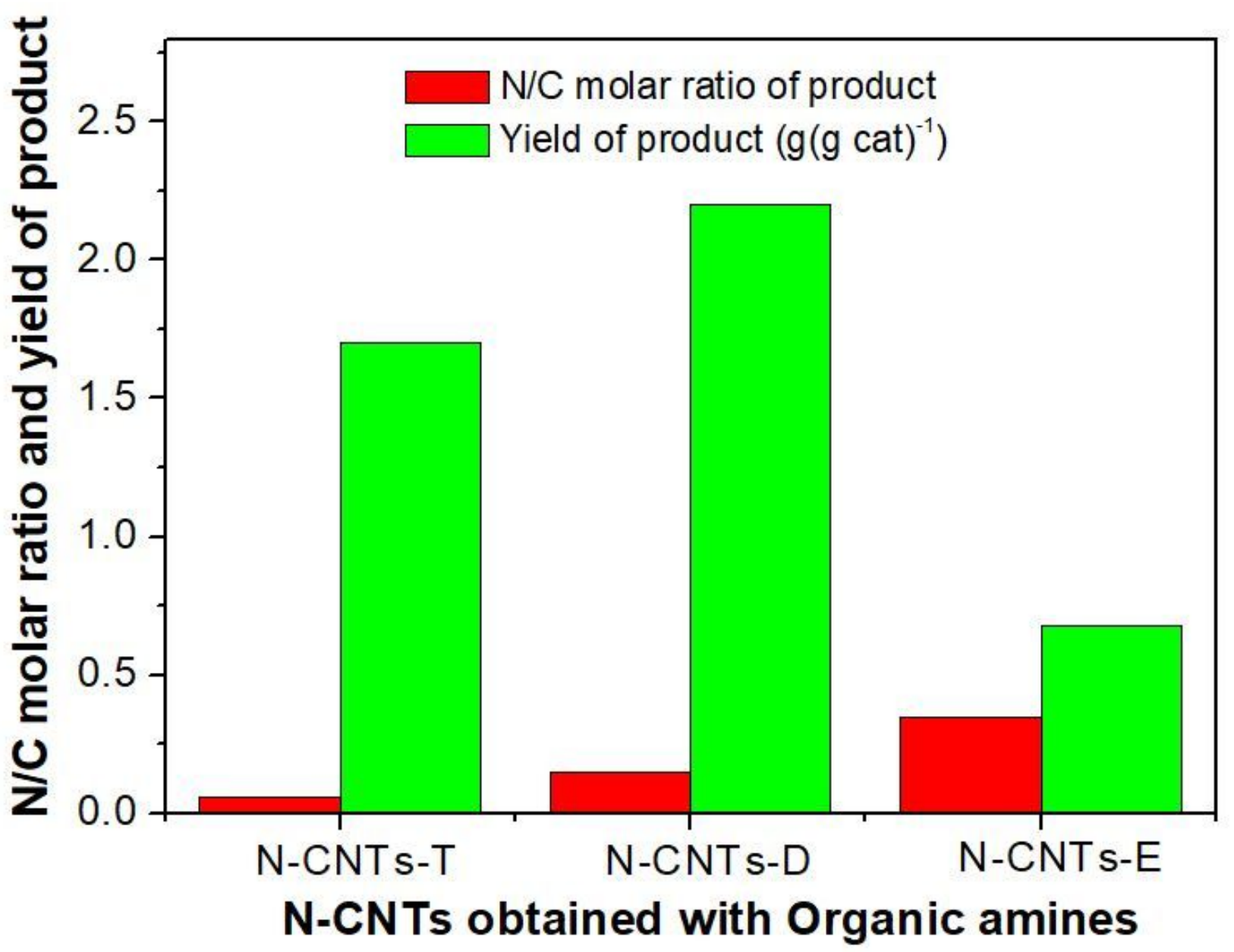

Figure 6

The effect of different organic amines on the formation of the N-CNTs. (a)N-CNTs-T, (b)N-CNTs-D, and (c)N-CNTs-E. 


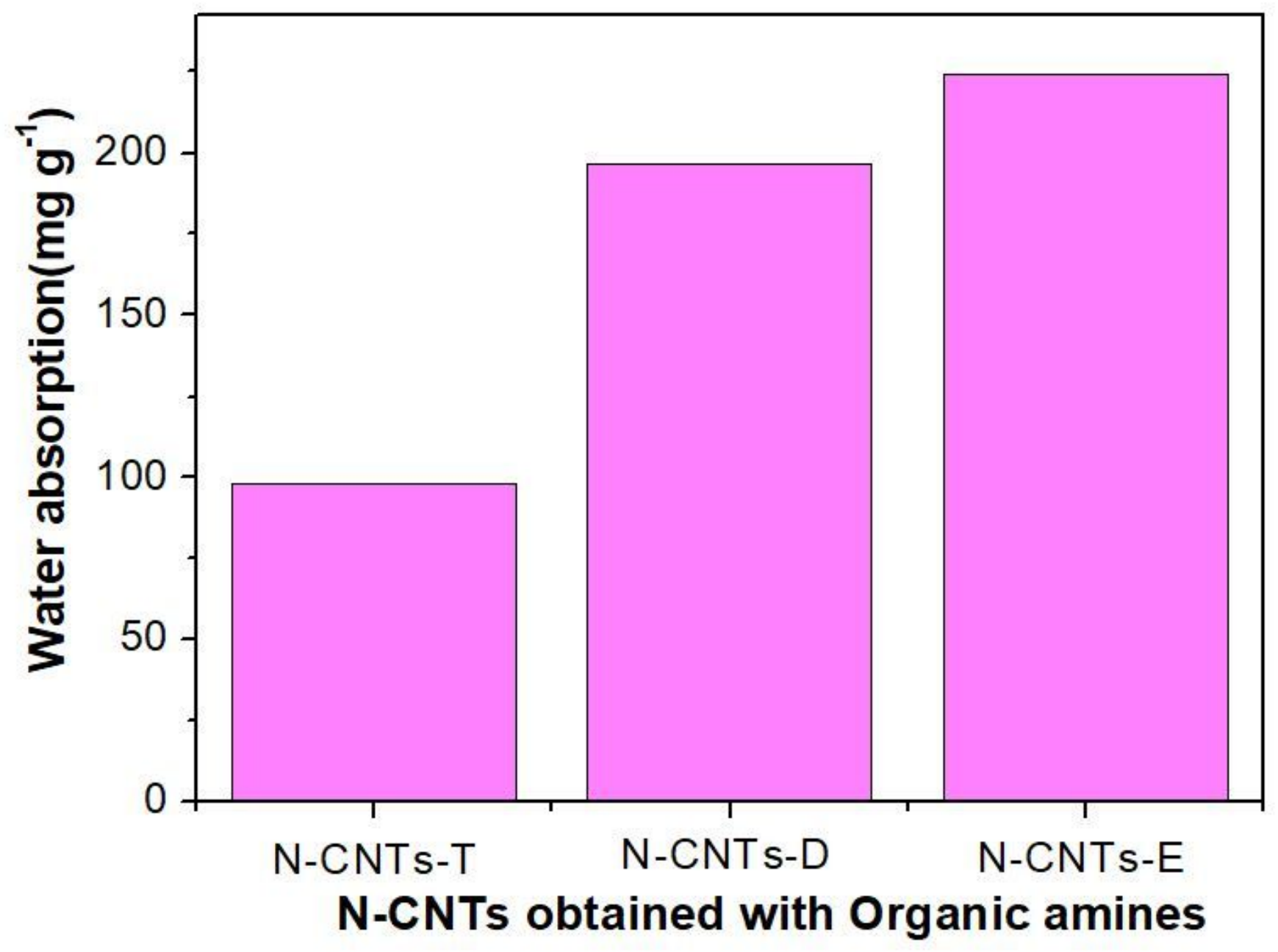

Figure 7

The water absorption of the N-CNTs prepared with different organic amines. (a)N-CNTs-T, (b)N-CNTs-D, and (c)N-CNTs-E. 


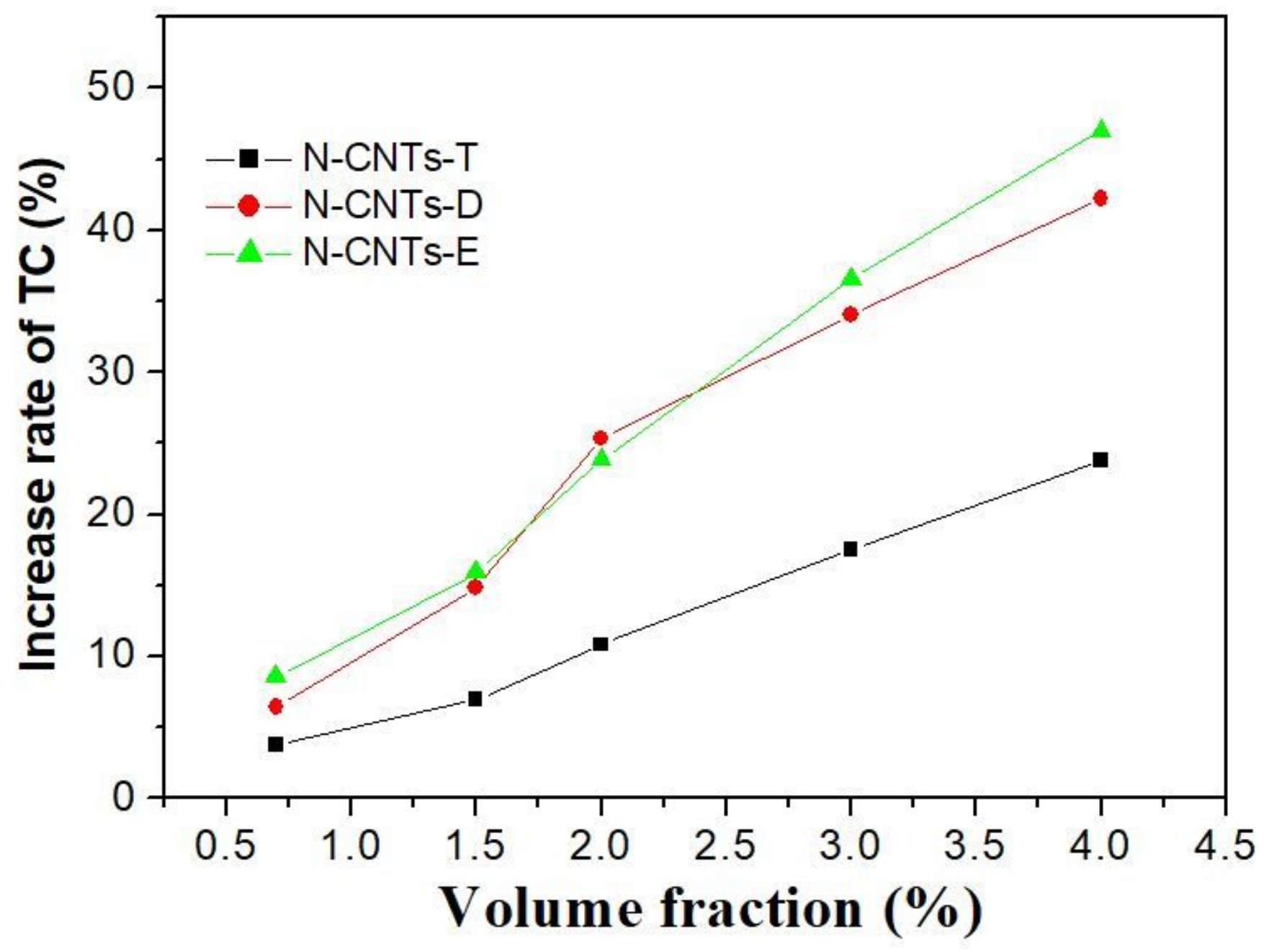

Figure 8

The effect of the N-CNTs prepared with different organic amines on TC of silicon matrix composites. (a)N-CNTs-T, (b)N-CNTs-D, and (c)N-CNTs-E. 